\title{
Transitivity Structure of Research Articles: Variations across Sections
}

\author{
Xindi Zheng ${ }^{1}$ \\ ${ }^{1}$ School of Foreign Languages and Literature, Beijing Normal University, Beijing, China \\ Correspondence: Xindi Zheng, School of Foreign Languages and Literature, Beijing Normal University, Beijing, \\ China.
}

Received: June 22, 2021

Accepted: July 13, 2021

Online Published: July 15, 2021

doi: 10.5539/elt.v14n8p8

URL: https://doi.org/10.5539/elt.v14n8p8

\begin{abstract}
This study investigates the transitivity structure of research articles and examines the variations of process types across sections, aiming to explore experiential meaning construction in academic discourse. The corpus for this study consists of ten applied linguistics research articles published from 2018 to 2020 in the top journals of the discipline. Features of the transitivity structure of the whole research articles are presented. The distribution of different process types is also examined in relation to the rhetorical purposes and stylistic features of the abstract, introduction, method, results and discussion, and conclusion sections. The findings reveal that transitivity structure could largely reflect the stylistic features of research articles, which are characterized as being informative and objective as well as interpersonal. Results also show that the distribution of process types may contribute to the regularity manifestation and purpose fulfillment of distinctive sections. This study has implications for both academic writers and academic writing courses.
\end{abstract}

Keywords: academic writing, process types, research articles, transitivity analysis, variations across sections

\section{Introduction}

In recent decades, English for Academic Purposes (EAP) has evolved rapidly and now become a major force in English teaching and research (Hyland, 2006, p. 1). Research of this line covers a wide range of academic communicative practices, such as classroom interactions, research genres, student writing, administrative practice, language teacher-faculty collaboration, second language publishing, practitioner identity, and critical thinking (Hyland, 2006, p. 1; Hyland \& Wong, 2019, p. 2). Among them, one staple genre which has been constantly examined is research article, which represents the institutionalized mechanism for knowledge presentation (Swales, 1990). The emerging trend of studies on research articles focuses on the interpersonal components and textual structures of this genre. Following the fashion to investigate the evidence of interactivity in academic texts (Hyland \& Jiang, 2017), many researchers paid attention to stance and engagement in research articles. Stance was extensively explored through examining writers' access to certain information and their certainty and attitudes towards the information (e.g., Hyland, 2001b; Hu \& Cao, 2015); whereas engagement was examined from the perspective of potential readers, concentrating on linguistic resources to involve readers into the academic practices (e.g., Hyland, 2001a; Jiang \& Ma, 2018). Other researchers investigated cohesion and coherence of research articles. Cohesion was explored in terms of theme-rheme structure (e.g., Ebrahimi, 2016; North, 2005) or lexical cohesion (e.g., Bondi, 2006); whereas research about coherence mainly investigated the use of reformulation markers and exemplificatory markers (e.g., Carrió-Pastor, 2013; Hyland, 2007).

However, the goals of research articles might not be fully fulfilled by interpersonal and textual components, without taking into consideration about the human experiences construed in this genre. In other words, the experiential meaning is also important in constructing disciplinary knowledge and putting research articles in the appropriate style (Halliday \& Martin, 1993; Martínez, 2001). To construe this type of meaning, selections are made from the transitivity system (Halliday, 1994, 2004, 2014). Although transitivity has been widely studied in stylistics and critical linguistics (e.g., Halliday \& Martin, 1993; Simpson, 1993), much less attention has been paid to the construal of human experiences in research articles. Despite this, there are still some notable exceptions worth mentioning. Martínez (2001) investigated the transitivity structure of experimental research articles from three disciplines to explore how process types characterized the genre and related to the presence and distance of writers. Although her initial intention was to examine the impersonality encoded in transitivity structure, her results revealed that a balance needed to be built between objectively presenting the findings and persuasively informing potential readers about the validity of the research (Martínez, 2001). More recently, from 
the perspective of functional stylistics, Zhang, Yang, and Ge (2014) conducted a research on the transitivity structure of medical research articles. Their findings showed supportive results that the stylistic features of research articles could be reflected by transitivity system and process selection may associate with the purposes and style of the genre. These two studies provided meaningful insights for further investigating the construction of experiential meaning in academic discourse.

The present study explores the transitivity structure of research articles through examining the choices of process types in different sections. The rationale is that each section of research articles has distinctive rhetorical purposes. As a regularized genre, research articles usually follow a typical structure to include the introduction, method, results, and discussion sections (Swales, 1990), with some variations in containing the abstract and conclusion sections. Abstract is an outline of the research, presenting the topic and major findings; introduction provides the purposes of the reported study, reviews background literature, and states the hypotheses to be explored; the method section informs the reader details of research design (including participants, materials, procedures, analysis, etc.); results and discussion section presents data descriptions, reports findings, and provides interpretations and explanations to results; conclusion restates the research, summarizes findings, and provides limitations and implications (Mackey \& Gass, 2005, pp. 7-15; Publication Manual of the American Psychological Association, 2020, p. 4). It may be necessary to analyze the transitivity structure in separate sections, in order to better understand the construction of experiential meaning in research articles and clarify the variations across sections.

The following research questions guide the study:

1) What are the features of transitivity structure in research articles?

2) How does transitivity structure relate to different sections of research articles?

\section{Theoretical Background}

The theoretical framework of transitivity system is provided by Systemic Functional Linguistics (SFL) (Halliday, 1994, 2004, 2014; Halliday \& Martin, 1993; Thompson, 1996). According to SFL, human being use language to talk about both "outer" and "inner" experiences of the world, and the experiential meaning of language is construed by transitivity system (Halliday, 2014, p. 214). By definition, the transitivity system "provides the lexicogrammatical resources for construing a quantum of change in the flow of events as a figure - as a configuration of elements centered on a process", which is expressed in processes, the participants involved, and certain circumstances (Halliday, 2014, p. 213). Six types of processes that represent human experiences were identified: material, mental, relational, behavioral, verbal, and existential processes (Halliday, 1994, 2004, 2014; Thompson, 1996).

Material processes are processes of doing-and-happening, usually describing concrete and tangible actions which take place with some input of energy. In these processes, one participant, the Actor, performs physical actions to another participant, the Goal. The participants (i.e., the Actor and the Goal) can be animate, inanimate, or abstract entities, and the material clauses can be transitive (including two participants) or intransitive (including one participant). One example of material process is shown in example (1):

\begin{tabular}{llll}
\hline (1) We & conducted & four studies & to answer each research question. (Kim, Crossley, \& Kyle, 2018) \\
\hline Actor & Process: material & Goal & Circumstance \\
\hline
\end{tabular}

Mental processes are concerned with the experience of human consciousness, representing emotion or reaction, cognition, perception, and desideration. These processes also involve two participants: the Senser (being endowed with consciousness and being able to feel, think, want, or perceive) and the Phenomenon (usually being realized by a thing, an act, or a fact and being the one which is felt, thought, wanted, or perceived), as is shown in example (2):

(2) Korpi and Farvardin (2016) found that certain branches of EI correlated strongly with specific features of L2 writing (complexity, accuracy, fluency). (Mavrou, 2020)

Senser Process: mental Phenomenon

Relational processes, or processes of being and having, serve to make characterization and identification. According to the potential for reversibility, relational processes are categorized into attributive relational processes and identifying relational processes. In a relation of attribution, the two participants, the Carrier and the Attribute, are not reversible; whereas in a relation of identification, the two participants, the Token and the Value, are reversible. Some examples are: 


\begin{tabular}{lll}
\hline (3) The effect of Condition & was & significant on Day 2... (Liu \& Hell, 2020) \\
\hline Carrier & Process: rel, attrib & Attribute \\
\hline
\end{tabular}

(4) Intelligibility is defined as the degree of a listener's actual comprehension of an utterance' (p. 478), ... (Moussalli \& Cardoso, 2020)

Token Process: rel, ident Value

Verbal processes are processes of saying, contributing to narrative creation through setting up dialogic passages. Three participants are involved in these processes: the Sayer, the Receiver, and the Verbiage. The Sayer is responsible for the verbal processes, which is typically but not necessarily conscious; the Receiver is the participant the saying is directed to; and the Verbiage functions as the content of what is said or the name of the saying, as illustrated in example (5):

\begin{tabular}{lll}
$\begin{array}{l}\text { (5) ...Kyle and } \\
\text { Crossley (2016) }\end{array}$ & reported & $\begin{array}{l}\text { that the indices can capture task-specific lexical features (e.g., } \\
\text { range, hypernymy) between integrated and independent } \\
\text { TOEFL Internet-based Test (iBT) writing tasks. (Eguchi \& } \\
\text { Kyle, 2020) }\end{array}$ \\
\hline Sayer & Process: verbal & Verbiage
\end{tabular}

Behavioral processes are about physiological and psychological behaviors, such as breathing, coughing, smiling, dreaming, and staring. These processes partly resemble material processes and partly resemble mental processes. One participant, the Behaver, is involved in behavioral clauses. As the Behaver is usually a conscious being, behavioral processes do not seem to be prominent in academic discourse.

Existential processes represent the existence or happening of entities and do not predicate anything else. Typically, an existential clause is realized by a There-construction containing a participant, the Existent, as in example (6):

\begin{tabular}{lll}
\hline (6) There & is & also one study that tackled the potential interaction between \\
& WMC, EI, and writing in L2 Spanish. (Mavrou, 2020) \\
\hline & Process: existential & Existent \\
\hline
\end{tabular}

Although Halliday $(1994,2004,2014)$ and Thompson (1996) provided criteria for distinguishing one type of processes from another, the identification of process types may not be straightforward. This is because some clauses could be classified under more than one process type, depending on their use in text. For example, verbs such as "indicate", "suggest", and "show" may be categorized as verbal processes when they have a Sayer preceding them and project the Verbiage, as is shown in example (7). They may also be identified as relational processes when functioning to relate abstract nominal participants. An example is provided in (8).

\begin{tabular}{lll}
\hline (7) ..., Kyle et & showed & $\begin{array}{l}\text { that, among others, range and meaningfulness can successfully } \\
\text { al. (2016) }\end{array}$ \\
& & $\begin{array}{l}\text { differentiate performances in Test-of-English-as-a-Foreign } \\
\text { Language (TOEFL) independent speaking from those in } \\
\text { integrated speaking tasks. (Eguchi \& Kyle, 2020) }\end{array}$ \\
\hline Sayer & Process: verbal & Verbiage \\
\hline
\end{tabular}

\begin{tabular}{ll}
$\begin{array}{l}\text { (8) Indices of } \\
\text { subordination }\end{array}$ & $\begin{array}{l}\text { fairly good separation between CEFR levels, particularly } \\
\text { for A1 versus B1, but also between adjacent levels (Figure } \\
\text { 2; Table S6 and S10). (Khushik \& Huhta, 2020) }\end{array}$ \\
\hline
\end{tabular}

\begin{tabular}{lll}
\hline Carrier & Process: rel, attrib & Attribute \\
\hline
\end{tabular}

\section{Research Design}

\subsection{Corpus}

The corpus consists of 10 research articles from applied linguistics discipline, with the total words being 79,984. For text selection, five leading journals were chosen based on the 2019 impact factors published by Web of Science. All the selected journals (i.e., Applied Linguistics, Modern Language Journal, Language Learning, Journal of Second Language Writing, and Computer Assisted Language Learning) were ranked as the top ten journals in this discipline. Two research articles were selected from each journal according to two criteria: 
First, all the selected articles were published between 2018 and 2020, representing the latest research status quo of the discipline.

Second, only articles based on empirical studies were included. In other words, all the selected research articles were either explicitly labelled as empirical research or followed the typical structure to include separate introduction, method, results and discussion, and conclusion sections.

All the selected research articles were transformed and saved in plain text format. Any words which, to a very large extent, could not reflect the linguistic features of the articles (including cover pages, tables, formulae, footnotes, endnotes, appendixes, information about project funding, acknowledgement, references, etc.) and messy codes were deleted. In this way, only the abstracts and the main body of research articles were retained to be analyzed. Then, all the selected articles were split according to their subtitles, in order to form five sub-corpora, which were in turn named as the abstract, introduction, method, results and discussion, and conclusion sub-corpus. The numbers of words of the sub-corpora were also counted. Table 1 lists the number of texts and number of words in each section and the whole research articles.

Table 1. Details of the Corpus

\begin{tabular}{lll}
\hline Section & Number of texts & Number of words \\
\hline Abstract & 10 & 1,876 \\
Introduction & 10 & 25,223 \\
Method & 10 & 17,992 \\
Results and discussion & 10 & 30,273 \\
Conclusion & 10 & 4,620 \\
Total & 10 & 79,984 \\
\hline
\end{tabular}

\subsection{Analysis}

Language is a complex system composed of a hierarchy of units, and each unit forms a rank (Halliday, 1994, 2004, 2014). As a separate rank, clause is the "primary channel of grammatical energy" (Halliday, 2004, p. 31). In the corpus, ranking clauses exist and function prototypically "as constituents of the higher unit" (Halliday, 2004 , p. 323). Meanwhile, embedded clauses also exist and rankshift to "function within the structure of a group" (Halliday, 2004, p. 426). In other words, in the rank scale, embedded clauses are not at the same level as ranking clauses (Thompson, 1996). In this research, embedded clauses were excluded from the analysis and finite verbs were identified in ranking clauses. For example:

(9) || The study investigates the linguistic basis of Common European Framework of Reference (CEFR) levels in English as a foreign language (EFL) learners' writing. ||| (Khushik \& Huhta, 2020)

(10) ||| The students came from two grades [[ that presumably represented A2 and B1 levels ]]. ||| (Khushik \& Huhta, 2020)

In example (9), one ranking clause, which is marked off by the symbol $\|$, was identified. In example (10), one clause complex, also marked off by the symbol $\|$, was identified, consisting of a ranking clause "The students came from two grades" and an embedded clause "that presumably represented A2 and B1 levels" marked by [[ and ]]. However, the embedded clause in (10) was a constituent of the preceding ranking clause, thus it was excluded from the analysis and only the ranking clause was focused on.

After all the ranking clauses were identified, they were classified according to process types, with reference to the categorization and definitions provided by Halliday $(1994,2004,2014)$ and Thompson (1996). For instance:

(11) ||| (1) Taken together, this study provides further evidence of the multidimensional nature of the construct of lexical sophistication; || (2) suggests || (3) that while some features of lexical sophistication may be domain general, $\|$ (4) others may be task specific; $\|$ (5) and provides a roadmap for the measurement of lexical sophistication in future studies of proficiency, development, and use.|| (Eguchi \& Kyle, 2020)

Example (11) was a clause complex consisting of five ranking clauses. Ranking clauses (1) and (5) were identified as material processes, as the verb "provides" reflected the doing-and-happening of the Actor "this study". Ranking clause (2) was identified as a verbal process, with the Sayer being "this study" and the verb "suggests" representing a verbal action here. Ranking clauses (3) and (4) were identified as relational processes, as the verb "be" established the relation between "some features of lexical sophistication" and "domain general" and 
"others" and "task specific"; in other words, the verb "be" helped to characterize the "features of lexical sophistication".

The corpus was coded by the researcher and the coding procedures involved two stages. First, one research article in the corpus was selected and coded for coder training. This research article contained more than four hundred ranking clauses, which was sufficient for establishing the familiarity and confidence in later coding procedures (Mackey \& Gass, 2005). It was coded twice and the Cohen's Kappa of the two coding results demonstrated an intra-coder consistency of 0.92. Second, all the ten research articles in the corpus were coded. The occurrence frequency and percentage of each process type were counted and calculated, and comparisons were made across sections. Accordingly, features of the whole research articles and distinctive sections were detected, expanding our understanding towards the transitivity structure of academic discourse.

\section{Results and Discussion}

\subsection{Overall Results}

All ranking clauses $(n=4301)$ were identified and categorized according to types of processes. Among the six process types, material processes were the most frequently employed in the corpus (1922, 44.69\%), and the second most frequently used type was relational processes $(1505,34.99 \%)$. The other four types of processes were used much less frequently in the following sequence: mental processes $(420,9.77 \%)$, verbal processes $(354$, $8.23 \%)$, existential processes $(83,1.93 \%)$, and behavioral processes $(17,0.40 \%)$. The extremely low frequency of the last type, behavioral processes, is in line with the finding of Martínez (2001) and Zheng et al. (2014). All these researchers suggested that it may not be necessary to take behavioral processes into consideration, as the low percentage of occurrence would not alter the results (Martínez, 2001) and could have relation to the contents of the research articles (Zheng et al., 2014). Thus, in this research, behavioral processes were excluded from statistical analysis and the number of ranking clauses under examination was reduced from 4301 to 4284 . Table 2 lists the frequencies and percentages of the five process types in the whole research articles and distinctive sections, and Figure 1 displays the percentages of process types across sections.

Table 2. Frequencies and Percentages of Process Types in Different Sections and the Whole Research Articles

\begin{tabular}{lllllll}
\hline & Abstract & Introduction & Method & Results and discussion & Conclusion & Total \\
\hline Material & $56(51.38 \%)$ & $556(41.15 \%)$ & $539(58.14 \%)$ & $672(41.13 \%)$ & $99(37.64 \%)$ & $1922(44.86 \%)$ \\
Mental & $5(4.59 \%)$ & $172(12.73 \%)$ & $60(6.47 \%)$ & $136(8.32 \%)$ & $47(17.87 \%)$ & $420(9.80 \%)$ \\
Relational & $32(29.36 \%)$ & $482(35.68 \%)$ & $271(29.23 \%)$ & $627(38.37 \%)$ & $93(35.36 \%)$ & $1505(35.13 \%)$ \\
Verbal & $14(12.84 \%)$ & $113(8.36 \%)$ & $31(3.34 \%)$ & $178(10.89 \%)$ & $18(6.84 \%)$ & $354(8.26 \%)$ \\
Existential & $2(1.83 \%)$ & $28(2.07 \%)$ & $26(2.80 \%)$ & $21(1.29 \%)$ & $6(2.28 \%)$ & $83(1.94 \%)$ \\
Total & 109 & 1351 & 927 & 1634 & 263 & 4284 \\
\hline
\end{tabular}

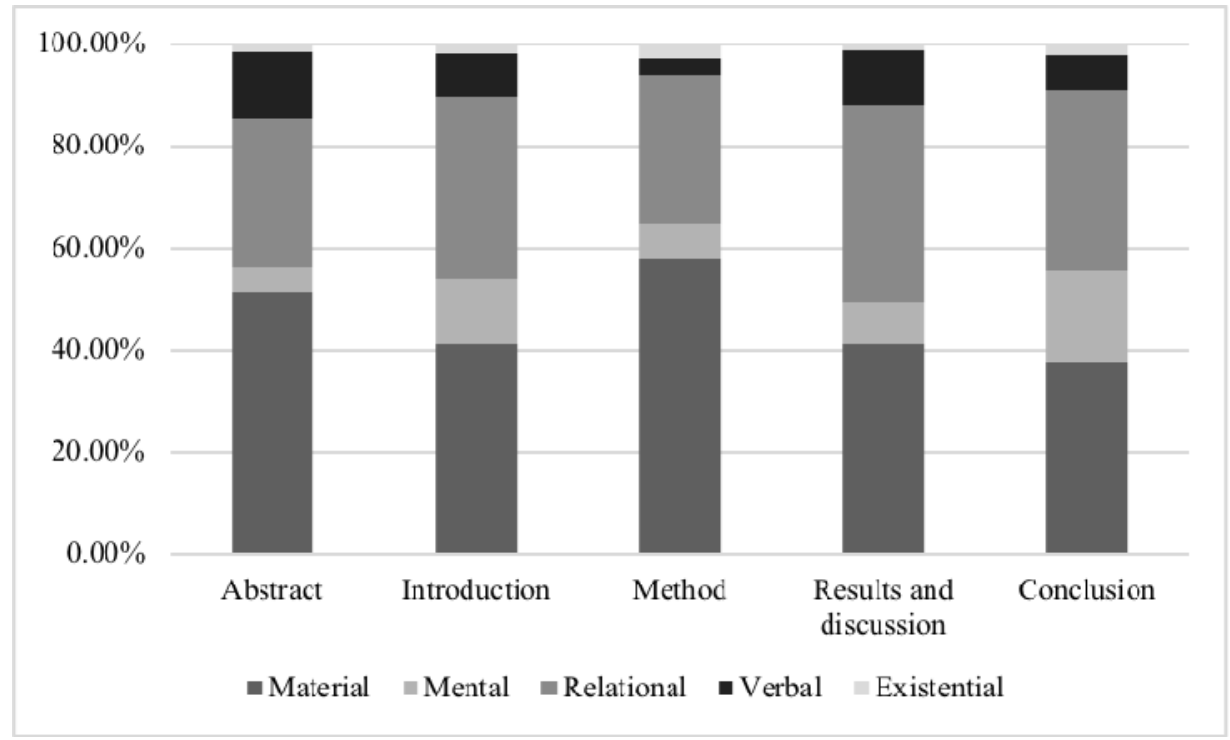

Figure 1. Percentages of Process Types across Sections of Research Articles 


\subsection{Variations across Sections}

As is shown in Table 2 and Figure 1, the five types of processes concentrated differently across sections. The abstract section had the highest percentage of verbal processes (12.84\%). Thirteen out of the fourteen instances of verbal processes reported the findings of the research, with most of the clauses having "(the) results" or "our results" as the Sayers. This finding could be predictable as the academic writers always condense important information and findings of their research in the abstract section (Ebrahimi \& Chan, 2015). For example:

(12) ||| (1) The results suggest || (2) that while some features of lexical sophistication (e.g., concreteness) may be task independent, || (3) others (e.g., frequency) may be task specific. || (Eguchi \& Kyle, 2020)

In example (12), three ranking clauses were identified. A verbal process occurred in ranking clause (1), with the Sayer "the results" being responsible for the process of saying: the "features of lexical sophistication" may be either "task independent" or "task specific". In this sense, ranking clause (2) and (3) in example (12) functioned as the Verbiage of the verbal process.

The introduction section of research articles contained relatively high percentages of verbal processes $(8.36 \%)$, mental processes $(12.73 \%$ ), and relational processes (35.68\%). This was consistent with the finding of Martínez (2001), who argued that the frequent use of these processes could be a result of the general function of the introduction section. In other words, the academic writers prepared the ground for their research by referring to previous research and acknowledging what has been done in literature (del Saz Rubio, 2011; Swales, 1990). Below are some examples extracted from the corpus:

(13) ||| (1) More recently, Bakker, Takashima, van Hell, Janzen, and McQueen (2014) demonstrated || (2) that consolidation occurs both within and across modalities. || (Liu \& Hell, 2020)

It may not be difficult to notice that participants of the verbal processes in the introduction section are different from those in the abstract section: most verbal processes in introduction had "other research" or "other researchers" as the Sayers. In example (13), ranking clause (1) was identified as a verbal process. The Sayers were a group of researchers who were responsible for the verbal process and the Verbiage "consolidation occurs both within and across modalities" presented their findings. Through employing verbal processes of this kind, the writers positioned themselves in relevant literature context (del Saz Rubio, 2011) and increased authority to their argumentation (Zheng et al., 2014).

(14) ||| (1) Kyle and Crossley (2015) found || (2) that n-gram frequencies and proportions were predictive of human ratings of L2 lexical proficiency... || (Kim et al., 2018)

As is illustrated in ranking clause (1) of example (14), mental processes in the introduction section were usually used to report findings of pre-established research. The verb "found" is concerned with human consciousness; in other words, the Senser, or the two researchers, "found" the Phenomenon "that n-gram frequencies and proportions were predictive of human ratings of L2 lexical proficiency".

(15) I|| ERP results showed a frontal LPC semantic priming effect immediately after learning, and a robust posterior LPC semantic priming effect 24 hours after learning... ||| (Liu \& Hell, 2020)

In example (15), one relational process was identified, as the verb "showed" here functioned to relate "ERP results" with two abstract nominal elements: "a frontal LPC semantic priming effect immediately after learning" and "a robust posterior LPC semantic priming effect 24 hours after learning". Processes like example (15) were also employed to acknowledge what has been done in previous research.

The method section had the highest percentage of material processes $(58.14 \%)$ and low percentages of mental processes $(6.47 \%)$, relational processes $(29.23 \%)$, and verbal processes $(3.34 \%)$. Similar results could be found in Zhang et al. (2014) and Martínez (2001), both of whom indicated that the method section was dominated by material processes and contained very low percentages of mental, relational, and verbal processes. Borrowing the term from Simpson (1993), Martínez (2001) regarded the method section as the most "actional" section in research articles. Examples from the corpus could provide supportive evidence to this characteristic:

(16) || (1) For recall, one of the researchers manually coded one page of randomly selected texts for each of the five features || (2) until 100 codes were assigned for each measure. ||| (3) These texts were then analyzed using Tregex and the procedures described above, $\|$ (4) and recall was calculated as the number of manually coded instances identified by the automated approach (true positives) divided by the number of agreements plus the number of disagreements (true positives plus false positives; in this case 100). ||| (5) The following recall scores were obtained: adjective (0.96), post-preposition (0.97), participle (0.95), possessive noun (0.94), and relative clause (0.91). ||| (Casal \& Lee, 2019) 
In example (16), the writers described the procedures to calculate "recall", which included two steps: manual coding and machine analysis. All the five ranking clauses were identified as material processes, with the first ranking clause containing the Actor (i.e., the researchers) and the Goal (i.e., the objects of the research) and the other four ranking clauses only containing the Goal.

One thing noticeable here is that in the method section, many processes were in passive constructions. Table 3 shows the frequencies and percentages of voice across sections. In the method section, the percentage of passive constructions $(43.26 \%)$ was nearly two-third to that of the active constructions $(56.74 \%)$, whereas in the rest four sections, the proportion between the two constructions was around 1:4. A further examination of the passive constructions in the method section showed that $94.26 \%$ of the omitted Actor could be interpreted as the writers or researchers. The absence of the Actor and the presence of concrete verbs (such as "assign", "analyze", "calculate", and "obtain" in example (16)) indicated that research methodology was presented with impersonality and the focus of this section was not the writers or the researchers but "the objects or creatures under manipulation and scrutiny" (Martínez, 2001, p. 237).

Table 3. Frequencies and Percentages of Voice in Different Sections of Research Articles

\begin{tabular}{llllll}
\hline & Abstract & Introduction & Method & Results and discussion & Conclusion \\
\hline Active & $89(81.65 \%)$ & $1093(80.90 \%)$ & $526(56.74 \%)$ & $1332(81.52 \%)$ & $224(85.17 \%)$ \\
Passive & $20(18.35 \%)$ & $258(19.10 \%)$ & $401(43.26 \%)$ & $302(18.48 \%)$ & $39(14.83 \%)$ \\
Total & 109 & 1351 & 927 & 1634 & 263
\end{tabular}

The results and discussion section contained the highest percentage of relational processes (38.37\%) and relatively high percentage of verbal processes $(10.89 \%)$. This could be attributed to the common practice that the results and discussion section is the section where the writers present the results and interpret their findings (Le \& Harrington, 2015). Therefore, the frequently appeared processes were typically employed to present the quantitative results and make evaluative comments or make connections with previous studies. For instance:

(17) || The table shows statistically significant increases in the use of reporting verbs in AL and engineering (LL $=352.20, \mathrm{p}<.001 ; \mathrm{LL}=46.75 ; \mathrm{p}<.001) \ldots \| \mid($ Hyland \& Jiang, 2019)

Example (17) was identified as one ranking clause containing a relational process. The verb "shows" was used to interpret the figures listed in a table, reporting the quantitative results to potential readers.

(18) || (1) The regression models also indicated || (2) that more proficient L2 learners tend to use a higher proportion of n-gram s found in the reference corpora n-gram lists (Kyle \& Crossley, 2015)... ||| (Kim et al., 2018)

In example (18), a verbal process was used to interpret "the regression models" in relation to another study, aligning the reported study with pre-established research and thus indicating that one of the central concerns of the results and discussion section is to make deliberation and reflection (Martínez, 2001). In this way, the credibility of the results and the significance of the research could be increased.

The conclusion section included the highest percentage of mental processes $(17.87 \%)$ and relatively high percentages of relational processes $(35.36 \%)$ and existential processes $(2.28 \%)$. This section is typically composed of research restatement, study consolidation, research implications, and future research recommendations (Swales, 2004). On the one hand, in order to contribute to the restatement and consolidation of the reported research, relational and existential processes were usually employed in an impersonal way, for making characterization and identification and clarifying the existence of certain entities. For instance:

(19) ||| Clausal complexity was shown to vary little across all grade tiers, both in terms of coordination and subordination. ||| (Casal \& Lee, 2019)

Example (19) was identified as a relational process. Through making characterization about the Carrier, "clausal complexity", the ranking clause restated the finding of the reported research. Also, this relational process was in passive construction, reflecting its impersonality.

(20) ||| Additionally, there are some limitations to the approaches used in these studies. || (Kim et al., 2018)

In example (20), the Existent "some limitations to the approaches used in these studies" was presented as the only participant, hiding the agency and indicating the possibilities of improvement in terms of research approaches. 
On the other hand, in the conclusion section, human consciousness could be reflected in ranking clauses about providing advice on research applications and future directions. In this sense, mental processes were adopted to make the section persuasive. This is illustrated in the following example:

(21) ||| In future research, we would like to examine the IPAs' ability to understand accented speech and be understood by the same speakers, using a wider variety of first and target languages. || (Moussalli \& Cardoso, 2020)

In example (21), the Senser "we" and the mental process "would like to" not only indicated the directions for future research, but also provided space for potential readers to accept the writers' idea.

\subsection{Discussion}

Research article is an important academic genre which contributes to the construction of disciplinary knowledge (Hyland, 2004; Swales, 1990). The stylistic features of this genre are generally characterized as being informative, objective, neutral, persuasive, and argumentative (e.g., Hyland, 2004; Swales, 1990; Zheng et al., 2014). Findings of this research reveal that transitivity structure could, to a large extent, reflect the stylistic features of research articles. Generally speaking, material processes are mostly employed in research articles, encoding the way people act and things happen in an objective way. Relational processes, the second most frequently appeared process type, serve to make characterization and identification, enabling potential readers to understand the information or knowledge presented in research articles. Taken together, these two process types account for around $80 \%$ of all the ranking clauses. Existential processes, although having a low percentage, also hide the agency and indicate the objectivity of research articles. The dominance of material and relational processes and the presence of existential processes could combinedly show that, as an established genre for research presentation and finding exchange, research articles have one main feature of being informative and objective. On the other hand, mental and verbal processes are concerned with human consciousness and narrative creation. The use of these two process types may be helpful to reflect the persuasive and argumentative functions of research articles, through establishing channels for dialogues between writers and potential readers. This indicates that interpersonal components are also important in the progresses of research articles (Hyland, 2001a).

The analysis also shows that the five sections display distinctive clusters in terms of process types, which contributes to the fulfillment of the rhetorical purposes and stylistic features of each section. The abstract section serves to inform potential readers about the contents and significant information of the reported research (Martín, 2003). It also functions to capture potential readers' attention and indicate whether the whole article merits further reading, or to convince journal editors to accept and publish the article (Ebrahimi \& Chan, 2015). In this sense, in the abstract section, the interpersonal concerns could not be overlooked and verbal processes are thus employed to make the section argumentative and persuasive. The introduction section is about background knowledge and approach directness (Swales, 1990). To project themselves at the beginning and prepare a ground for the reported research (del Saz Rubio, 2011), writers usually employ mental, relational, and verbal processes. These types of processes could enable them to provide authoritative information about the territory being investigated, the findings of pre-established research, and the significance of their study. In the method section, writers typically explain research methodology and show the standardization of their research in a neutral and objective way (Martínez, 2003). The high percentage of material processes and low percentages of mental, relational, and verbal processes could reflect that academic writers intend to express objectivity and lower the degree of subjectivity and personal evaluation. Meanwhile, the high percentage of passive constructions in the method section could also enhance objectivity. In social and behavioral sciences, the results and discussion section play a key role (Le \& Harrington, 2015). It is here the writers present their findings, make interpretation and evaluation on data obtained in relation to problems under investigation, thus trying to establish the relationship between their findings and others' findings and contribute to knowledge construction (Martínez, 2003). In this sense, writers tend to on the one hand use relational processes to objectively and accurately report the information provided and on the other hand employ verbal processes to establish alignment with other researchers and potential readers. In the conclusion section, the high percentages of relational and existential processes could be attributed to the purpose of making objective summaries of the whole articles. The high percentage of mental processes reveals that the conclusion section at the same time contains interpersonal components, particularly when presenting the significance or contribution of the reported study and the insights for application and future research (Sheldon, 2019).

\section{Conclusion}

This research aims to explore experiential meaning construction in academic discourse. Specifically, we expand transitivity analysis into research articles and investigate the choices of process types across sections. Ten 
research articles from the applied linguistics discipline were examined in terms of transitivity structure. The findings reveal that the stylistic features of research articles could be largely reflected by the use of different process types. One main feature of research articles is being informative and objective, which could be supported by the finding that material and relational processes are dominant and existential processes are present. Meanwhile, interpersonal components of the genre could be reflected by the employment of mental and verbal processes. Our findings also reveal that the distribution of process types across sections could help to manifest the stylistic regularities and fulfill the goals of the sections. Writers use different types of processes to present impersonal information or make persuasive argumentation, making the sections function properly according to their distinctive rhetorical purposes.

The present study has some pedagogical implications. First, academic writers could take advantage of the findings to advocate writing strategies, especially those who intend to publish their research in English language journals. With the recognition of the process type distribution across sections, it may be necessary for academic writers to employ appropriate types of processes to unpack information according to the rhetorical purposes and stylistic features of each section. Furthermore, although the size of the corpus is limited, our findings indicate the links among linguistic choices, experiential meaning, and genre features. Following this, academic writing courses may include activities to examine the transitivity structure of research articles and build up relationship between process types and the genre features of distinctive sections. These activities could raise learners' awareness of the experiential meaning realized by different types of processes, improve their understanding towards the underlying reasons of linguistic choices, and thus prepare them for better participating in academic discourse community.

\section{References}

Bondi, M. (2006). A case in point: Signal of narrative development in business and economics. In K. Hyland \& M. Bondi (Eds.), Academic Discourse across Disciplines (pp. 49-74). Berlin: Peter Lang.

Carrió-Pastor, M. (2013). A contrastive study of the variation of sentence connectors in academic English. Journal of English for Academic Purposes, 12, 192-202. https://doi.org/10.1016/j.jeap.2013.04.002

Casal, J., \& Lee, J. (2019). Syntactic complexity and writing quality in assessed first-year L2 writing. Journal of Second Language Writing, 44, 51-62. https://doi.org/10.1016/j.jslw.2019.03.005

del Saz Rubio, D. (2011). A pragmatic approach to the macro-structure and metadiscoursal features of research article introductions in the field of agricultural sciences. English for Specific Purposes, 30, 258-271. https://doi.org/10.1016/j.esp.2011.03.002

Ebrahimi, S. (2016). Across disciplinary study of marked theme in method sections. Journal of Teaching English for Specific and Academic Purposes, 4(3), 689-699.

Ebrahimi, S., \& Chan, S. (2015). Research article abstracts in applied linguistics and economics: Functional analysis of the grammatical subject. Australian Journal of Linguistics, 35(4), 381-397. https://doi.org/10.1080/07268602.2015.1070660

Eguchi, M., \& Kyle, K. (2020). Continuing to explore the multidimensional nature of lexical sophistication: The case of oral proficiency interviews. The Modern Language Journal, 104(2), 381-400. https://doi.org/10.1111/modl.12637

Halliday, M. A. K. (1994). An Introduction to Functional Grammar (2nd ed.). London: Edward Arnold.

Halliday, M. A. K. (2004). An Introduction to Functional Grammar (3rd ed.). London: Hodder Arnold.

Halliday, M. A. K. (2014). Halliday's Introduction to Functional Grammar (4th ed.). London and New York: Routledge. https://doi.org/10.4324/9780203783771

Halliday, M. A. K., \& Martin, J. R. (1993). Writing Science: Literacy and Discursive Power. London: The Falmer Press.

Hu, G., \& Cao, F. (2015). Disciplinary and paradigmatic influences on interactional metadiscourse in research articles. English for Specific Purposes, 39, 12-25. https://doi.org/10.1016/j.esp.2015.03.002

Hyland, J., \& Jiang, F. (2017). Is academic writing becoming more informal? Journal of English for Academic Purposes, 45, 40-51. https://doi.org/10.1016/j.esp.2016.09.001

Hyland, K. (2001a). Bringing in the reader addressee features in academic articles. Written Communication, 18(4), 549-574. https://doi.org/10.1177/0741088301018004005 
Hyland, K. (2001b). Humble servants of the discipline? Self-mention in research articles. English for Specific Purposes, 20, 207-226. https://doi.org/10.1016/S0889-4906(00)00012-0

Hyland, K. (2004). Disciplinary Discourse: Social Interactions in Academic Writing. Michigan: The University of Michigan Press.

Hyland, K. (2006). English for Academic Purposes: An Advanced Resource Book. London and New York: Routledge. https://doi.org/10.4324/9780203006603

Hyland, K. (2007). Applying a gloss: Exemplifying and reformulating in academic discourse. Applied linguistics, 28(2), 266-285. https://doi.org/10.1093/applin/amm011

Hyland, K., \& Jiang, F. (2019). Points of reference: Changing patterns of academic citation. Applied Linguistics, 40(1), 64-85. https://doi.org/10.1093/applin/amx012

Hyland, K., \& Wong, L. (2019). Specialised English: New Direction in ESP and EAP Research and Practice. London and New York: Routledge.

Jiang, F., \& Ma, X. (2018). 'As we can see': Reader engagement in $\mathrm{PhD}$ candidature confirmation reports. Journal of English for Academic Purposes, 35, 1-15. https://doi.org/10.1016/j.jeap.2018.05.003

Khushik, G., \& Huhta, A. (2020). Investigating syntactic complexity in EFL Learners' writing across common European framework of reference levels A1, A2, and B1. Applied Linguistics, 41(4), 506-532. https://doi.org/10.1093/applin/amy064

Kim, M., Crossley, S., \& Kyle, K. (2018). Lexical sophistication as a multidimensional phenomenon: Relations to second language lexical proficiency, development, and writing quality. The Modern Language Journal, 102(1), 120-141. https://doi.org/10.1111/modl.12447

Le, T., \& Harrington, M. (2015). Phraseology used to comment on results in the discussion section of applied linguistics quantitative research articles. English for Specific Purposes, 39, 45-61. https://doi.org/10.1016/j.esp.2015.03.003

Liu, Y., \& Hell, J. (2020). Learning novel word meanings: An ERP study on lexical consolidation in monolingual, inexperienced foreign language learners. Language Learning, 70(2), 45-74. https://doi.org/10.1111/lang.12403

Mackey, A., \& Gass, S. (2005). Second Language Research: Methodology and Design. New Jersey: Lawrence Erlbaum Associates.

Martín, P. (2003). A genre analysis of English and Spanish research paper abstracts in experimental social sciences. English for Specific Purposes, 22, 23-43. https://doi.org/10.1016/S0889-4906(01)00033-3

Martínez, I. (2001). Impersonality in the research article as revealed by analysis of the transitivity structure. English for Specific Purposes, 20, 227-247. https://doi.org/10.1016/S0889-4906(00)00013-2

Martínez, I. (2003). Aspects of theme in the method and discussion sections of biology journal articles in English. Journal of English for Academic Purposes, 2, 103-123. https://doi.org/10.1016/S1475-1585(03)00003-1

Mavrou, I. (2020). Working memory, executive functions, and emotional intelligence in second language writing. Journal of Second Language Writing, 50, 1-13. https://doi.org/10.1016/j.jslw.2020.100758

Moussalli, S., \& Cardoso, W. (2020). Intelligent personal assistants: Can they understand and be understood by accented L2 learners? Computer Assisted Language Learning, 33(8), 865-890. https://doi.org/10.1080/09588221.2019.1595664

North, S. (2005). Disciplinary variation in the use of theme in undergraduate essays. Applied Linguistics, 26(3), 431-452. https://doi.org/10.1093/applin/ami023

Publication Manual of the American Psychological Association. (2020). Washington: American Psychological Association.

Sheldon, E. (2019). Knowledge construction of discussion/conclusion sections of research articles written by English L1 and L2 and Castilian Spanish L1 writers. Journal of English for Academic Purposes, 37, 1-10. https://doi.org/10.1016/j.jeap.2018.11.002

Simpson, P. (1993). Language, Ideology and Point of View. London and New York: Routledge. https://doi.org/10.4324/9780203312612 
Swales, J. (1990). Genre Analysis: English in Academic Research Settings. Glasgow: Cambridge University Press.

Swales, J. (2004). Research Genre: Explorations and Applications. Cambridge: Cambridge University Press. https://doi.org/10.1017/CBO9781139524827

Thompson, G. (1996). Introducing Functional Grammar. London: Edward Arnold.

Zheng, S., Yang, A., \& Ge, G. (2014). Functional stylistic analysis: Transitivity in English-medium medical research articles. Internal Journal of English Linguistics, 4(2), 12-25. https://doi.org/10.5539/ijel.v4n2p12

\section{Copyrights}

Copyright for this article is retained by the author(s), with first publication rights granted to the journal.

This is an open-access article distributed under the terms and conditions of the Creative Commons Attribution license (http://creativecommons.org/licenses/by/4.0/). 